\title{
Condena judicial contra el ex Presidente Alberto Fujimori: mensaje contra la impunidad y nuevo capítulo en la historia del Perú contemporáneo
}

Este comentario, junto a los documentos que analiza, está disponible en www.anuariocdh.uchile.cl

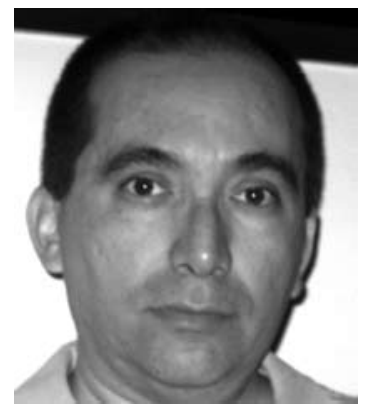

\begin{abstract}
David Lovatón Palacios
Abogado. Magíster en derecho constitucional por la Pontificia Universidad Católica del Perú (PUCP). Trabaja desde hace muchos años en el Instituto de Defensa Legal (IDL) del Perú, del que actualmente es su director general. Profesor principal en la Facultad de Derecho de la PUCP y ha sido profesor invitado en otras universidades y en la Academia de la Magistratura.

lovaton@idl.org.pe
\end{abstract}

\section{RESUMEN}

El artículo analiza desde la perspectiva del derecho de los derechos humanos y desde la posición singular de un abogado que pertenece a una de las organizaciones de derechos humanos que participó representando a "la parte civil" (las víctimas), el proceso judicial seguido en contra de Alberto Fujimori. La mirada de este trabajo es, por sobre todo, la de un testigo de un proceso judicial ejemplar que duró 16 meses que da cuenta de la perseverancia de los familiares de las víctimas, del desempeño de los abogados de derechos humanos y del contexto histórico político de los noventa.

"1 ${ }^{\circ}$. ¿Está probado que el acusado, nacido en el Perú, de padres japoneses, tiene doble nacionalidad: peruana y japonesa, y que en nuestro país su nombre es ALBERTO FUJIMORI FUJIMORI y en Japón es Kenya Fujimori? Sí lo está".

\section{Antecedentes}

Alberto Fujimori Fujimori asumió la Presidencia el 28 de julio de 1990, después de unas elecciones en las que venció democráticamente al escritor peruano Mario Vargas Llosa. No obstante, una vez en el poder, rápidamente abandonó sus promesas electorales en materia económica y aplicó una política de shock financiero muy similar a la anunciada por Vargas Llosa durante su campaña electoral. Fujimori aceleradamente optó por un estilo autoritario y de confrontación con los otros poderes del Estado, al punto de rebautizar al Palacio de Justicia como el "Palacio de la injusticia", capitalizando así el gran desprestigio de la justicia peruana en la ciudadanía. Finalmente, en el campo de la lucha antisubversiva, se rodeó de oscuros personajes -como el ex capitán del Ejército Vladimiro Montesinos Torres, expulsado del ejército en los setenta-, anunció una nueva estrategia y enfatizó su liderazgo como jefe supremo de las Fuerzas Armadas.

En esta escalada autoritaria, el 5 de abril de 1992 Fujimori dio un golpe de Estado, cerrando el Parlamento, el Poder Judicial, el Tribunal Constitucional y otras entidades públicas. Justificó esta 
medida como una acción necesaria para combatir mejor el terrorismo y la corrupción. Sólo la presión internacional hizo que Fujimori se comprometiera con un cronograma formal de retorno de la democracia, lo que no le impidió consolidar un régimen autoritario que le permitió reelegirse en dos ocasiones consecutivas en los años 1995 y 2000, y controlar y cooptar las Fuerzas Armadas, el Parlamento, el Poder Judicial, el Ministerio Público, el sistema electoral y los medios de comunicación masivos más importantes. La re-reelección del año 2000 fue tan escandalosa que la Misión de Observación Electoral de la Organización de Estados Americanos, presidida por el guatemalteco Eduardo Stein, concluyó que dichas elecciones no habían sido "ni justas ni limpias"1.

Poco tiempo después, en septiembre del 2000 se hizo público un "vladivideo" 2 en el que se aprecia al entonces asesor presidencial Vladimiro Montesinos entregando dinero a un parlamentario para que se pasara a las filas del oficialismo. El escándalo que se generó a partir de estos hechos, obligaron a Fujimori a destituir a Montesinos y a anunciar el adelanto de las elecciones. Pocos días después, Montesinos huyó clandestinamente del país previo pago en efectivo de una "indemnización" de U\$ 15 millones por sus años de servicio a Fujimori.

Jaqueado públicamente y huérfano de su principal y más poderoso aliado (Montesinos), Fujimori salió del país bajo el pretexto de asistir a la reunión de APEC en el reino de Brunei (Asia), pero intempestivamente cambió de itinerario y viajó a Japón, donde se amparó gracias a su doble nacionalidad japonesa, de la que nadie tenía conocimiento. Una vez en Japón, renunció vía fax a la Presidencia de la República. No obstante, el Parlamento no aceptó su renuncia y declaró vacante el cargo por "incapacidad moral”. Además, conforme con lo dispuesto en la Constitución, lo inhabilitó por diez años para ejercer cualquier cargo público. Este vergonzoso pasaje de nuestra historia nacional es tan grave que la sentencia condenatoria comenzó señalando:

" $4^{\circ}$. ¿Está probado que el acusado ALBERTO FUJIMORI FUJIMORI renunció a la Presidencia de la República desde Tokio el diecinueve de noviembre de dos mil, pero esta renuncia no fue aceptada por el Congreso y, por el contrario, declaró la vacancia presidencial por incapacidad moral? Sí lo está".

Fujimori permaneció refugiado en Japón con la complicidad y protección del gobierno de ese país hasta noviembre del 2005, momento en que viajó sorpresivamente desde Tokio a Santiago de Chile en un vuelo privado. Repuestas de la sorpresa inicial y ante el pedido del Gobierno peruano, las autoridades chilenas lo detuvieron y se inició un largo proceso de extradición ante la Corte Suprema de Chile, que en septiembre del 2007 y en segunda instancia, dio luz verde a la solicitud de extradición del Gobierno peruano por siete de los trece casos por cargos criminales que presentó el Perú. Entre éstos estaban cuatro casos de corrupción y tres casos de derechos humanos: (i) la "matanza de Barrios Altos", (ii) la "matanza de La Cantuta" y (iii) "sótanos del SIE" (sobre los secuestros del periodista Gustavo Gorriti y el empresario Samuel Dyer).

Fujimori retornó al Perú el 22 de septiembre del 2007 en calidad de detenido y fue recluido en un establecimiento penitenciario que se habilitó exclusivamente para él -en su condición de ex Presidente de la República - en el cuartel de la Dirección de Operaciones Especiales (DIROES) de

1 STEIN, Eduardo. La OEA por primera vez. Entrevista publicada Revista Ideele (127); abril-mayo del 2000, Instituto de Defensa Legal, Lima, p. 40: "[...] esta misión no considera que haya sido una pelea equitativa y justa y no considera que el conjunto de irregularidades, insuficiencias y problemas represente una contienda electoral ajustada a los comportamientos democráticos estándares... y todo ello se sumó a una idea de que algo opaco, algo siniestro estaba ocurriendo...".

2 Video filmado ilegal e inconsultamente por Vladimiro Montesinos de las numerosas reuniones o conversaciones que tuvo con muchos personajes. 
la Policía Nacional del Perú, en la ciudad de Lima. En ese mismo lugar, el Poder Judicial habilitó una sala especial de juzgamiento.

La legislación peruana dispone que para juzgar a un ex Presidente de la República, la Corte Suprema debe conformar una sala especial ad hoc, compuesta por tres jueces supremos que lo juzguen en primera instancia, y una sala penal ordinaria de la Corte Suprema -conformada por cinco jueces supremos- será la segunda instancia. En el caso de Fujimori, el entonces Presidente de la Corte Suprema convocó a algunos de los mejores jueces supremos y conformó una Sala especial con los supremos Víctor Prado y Hugo Príncipe y fue presidida por el juez supremo César San Martín. Esta composición inspiró confianza en todos los sectores, incluyendo a la defensa del ex mandatario. Esta sala especial tomó la sensata decisión de acumular todos los casos materia de la extradición en tres procesos: un "mega proceso" sobre derechos humanos, otro "mega proceso" de corrupción y uno específico referido a la compensación o indemnización por tiempo de servicios (CTS) de U\$ 15 millones que Fujimori pagó a Montesinos con dineros del Estado.

El proceso judicial por violaciones a los derechos humanos comenzó simbólicamente el 10 de diciembre del 2007, Día internacional de los derechos humanos y duró 16 meses. Fue un proceso ejemplar por varias razones: por el respeto a las garantías del debido proceso; la profusa actuación probatoria de las partes, publicidad del caso y el ordenado acceso de la prensa. El 7 de abril del 2009 -fecha muy cercana al 5 de abril, día que Fujimori dio el golpe de Estado en el año 1992- la Sala especial dictó sentencia condenando a Alberto Fujimori Fujimori a 25 años de pena privativa de libertad por encontrarlo responsable de las matanzas de Barrios Altos y La Cantuta y el secuestro agravado de Gustavo Gorriti y Samuel Dyer, condena que se cumplirá el 10 de febrero del año 2032. Fujimori apeló el fallo y el 30 de diciembre del 2009, mientras estábamos elaborando el presente artículo, la Primera Sala Penal de la Corte Suprema confirmó en todos sus extremos la sentencia de primera instancia.

\section{Algunas cifras sobre la sentencia ${ }^{3}$}

La sentencia emitida el 7 de abril del 2009 consta de 711 páginas, 830 párrafos organizados en 4 partes y 23 capítulos, 1258 citas a pie de página, un índice y una parte inicial o preliminar denominada "cuestiones de hecho" de 40 páginas y 247 párrafos. Esta última es una suerte de resumen de los hechos que el Tribunal consideró probados durante el proceso y que por su presentación pedagógica puede convertirse a futuro en una fuente para conocer la historia del Perú contemporáneo en escuelas y universidades. Pese a la complejidad jurídico-penal del caso, el Tribunal intentó con esta parte inicial de "cuestiones de hecho" que lo central de su decisión fuese comprendida por las/los ciudadanos y no sólo por jueces y abogados.

La voluminosa sentencia de primera instancia es muy ordenada, clasificada por párrafos, capítulos y partes, con subtítulos para facilitar la lectura y, sobre todo, con una línea argumental muy sólida y basada en fuentes de derecho autorizadas de derecho internacional de los derechos humanos, jurisprudencia nacional y de otros ordenamientos jurídicos, doctrina nacional y extranjera, documentos desclasificados del Gobierno de los Estados Unidos y las opiniones de expertos vertidas durante el juicio o alcanzadas gracias a amicus curiae.

Por su parte, la sentencia de segunda instancia es un documento de 266 páginas dividido en tres partes y nueve capítulos, y de sólidos argumentos jurídicos. Esta sentencia fue emitida por la Primera Sala Penal de la Corte Suprema presidida por el juez Duberlí Rodríguez.

3 Las sentencias de primera y de segunda instancia pueden ser consultadas y bajadas de varios sitios web; uno de ellos es el del Poder Judicial peruano: www.pj.gob.pe 
Finalmente, es importante resaltar el rol clave que jugó el Ministerio Público (los fiscales supremos) en sustentar una acusación penal contra Fujimori sólida y basada en una investigación documental, periodística y testimonial, que supuso reconstruir la historia del Perú durante la década del noventa; especial mención merece el fiscal supremo Avelino Guillén que luego recibió el Premio nacional de derechos humanos 2009 otorgado por la Coordinadora Nacional de Derechos Humanos.

\section{Trascendencia nacional e internacional de la sentencia}

En primer lugar, la sentencia es una forma de desagravio para las víctimas y familiares de las matanzas de Barrios Altos y La Cantuta, quienes durante años fueron estigmatizadas como terroristas - la maquinaria mediática del desactivado Servicio de Inteligencia Nacioal (SIN) los acusó de ser senderistas e inició contra ellos un hostigamiento judicial, policial y de amenazas constantes. Por ello, una de las solicitudes explícitas de la defensa de las víctimas y sus familiares, fue que la sentencia también contemplara medidas de "satisfacción" para las víctimas, como la verificación de los hechos y la revelación pública y completa de la verdad, el restablecimiento de la dignidad, la reputación y los derechos de las víctimas y de las personas estrechamente vinculadas con ellas o una disculpa pública ${ }^{4}$. Al respecto, la sentencia accedió a esta solicitud de la siguiente manera:

"804… Es suficiente, sin embargo, a estos efectos, y como consecuencia de la declaración de hechos probados, afirmar que no existe evidencia alguna, más allá de la insinuación -sin aval indiciario que la justifique- formulada por alguno de los participantes en los hechos, que siquiera remotamente pueda llevar a sospechar que las víctimas estarían vinculadas al PCP-SL e involucradas en determinados atentados con propósito terrorista" ${ }^{5}$.

En segundo lugar, la sentencia también es una reivindicación para todas las personas e instituciones (organismos de derechos humanos, algunos periodistas y medios independientes) que fueron objeto de persecución, hostigamiento y amenazas de parte y algunos políticos y militares, como el ex vicepresidente Máximo San Román y el general Rodolfo Robles, quienes fueron testigos claves en el proceso. Además, estas personas e instituciones durante años denunciaron la existencia de una estrategia de "guerra sucia" por parte del régimen fujimorista para combatir a Sendero Luminoso, del grupo Colina y la concentración del poder en manos de Fujimori y Montesinos, lo que fue sistemáticamente negado por el régimen que manipuló groseramente el Parlamento, el Poder Judicial, el fuero militar y la prensa para encubrir a los principales responsables, al punto que la sentencia desarrolló en extenso la actividad de encubrimiento de la maquinaria fujimontesinista. En este sentido, la sentencia constató:

" $589^{\circ}[\ldots]$ En puridad de verdad, fueron los órganos de prensa los que, como consecuencia de sus indagaciones, advirtieron a la opinión pública de los posibles responsables de tan grave suceso. El Estado, por su parte, y en especial las FFAA, optaron oficialmente por negar los hechos y cuestionar o intentar rebatir inmediatamente las informaciones que progresivamente iban apareciendo en diversos diarios y revistas".

En tercer lugar, la sentencia fue una forma de reivindicación del propio Poder Judicial y el Ministerio Público peruanos los cuales, lamentablemente hasta hoy, inspiran desconfianza en la ciudadanía por su lentitud y la corrupción aún muy arraigada, a pesar del esfuerzo de algunos jueces y fiscales

4 Esta petición se basó en la resolución sobre "Principios y directrices básicos sobre el derecho de las víctimas de violaciones manifiestas de las normas internacionales de derechos humanos y de violaciones graves del derecho internacional humanitario a interponer recursos y obtener reparaciones", aprobada por la Asamblea General de Naciones Unidas de fecha veintiuno de marzo de dos mil seis en su Sexagésimo Período de Sesiones. Específicamente, sobre el principio 22.

5 Énfasis añadido. 
honestos. Hay que recordar que uno de los temas que fueron materia de debate durante el proceso de extradición ante la Corte Suprema de Chile fue, precisamente, si el sistema judicial peruano tenía la suficiente capacidad e independencia para juzgar a Alberto Fujimori. Afortunadamente, la Sala especial de la Corte Suprema peruana estuvo a la altura de las circunstancias y cumplió con creces el mandato que se le confirió: Ilevar adelante un proceso judicial ejemplar y emitir una sólida sentencia. En otras palabras, absolvió las dudas razonables que existían sobre si tendría o no la suficiente capacidad e independencia para juzgar a un ex Presidente de la República. Hay que reconocer, sin embargo, que este proceso y sentencia ejemplares no son aún moneda corriente en el sistema judicial peruano, pero demuestran que a pesar de las grandes limitaciones y problemas endémicos que padece la justicia en el Perú, es posible asumir con éxito este tipo de retos. A mayor abundamiento, no es la primera vez que ha superado un desafío como éste, ya que logró condenar en democracia a las cúpulas de Sendero Luminoso y el Movimiento Revolucionario Túpac Amaru (MRTA), a Montesinos y a muchos alfiles del régimen fujimorista.

En cuarto lugar, la sentencia también es un reconocimiento a la comunidad internacional. Por una parte, sin el otorgamiento de la extradición por parte de la Corte Suprema chilena no habría sido posible juzgar a Fujimori. Por otra, las recomendaciones y decisiones del sistema interamericano de derechos humanos - la más importante caja de resonancia internacional de las denuncias en contra del régimen- fueron una fuente legal importante no sólo para la sentencia bajo comentario, sino para decisiones judiciales previas que sentaron los precedentes que ayudaron al juzgamiento de Fujimori (como la sentencia de la sala superior presidida por la intachable magistrada Inés Villa que condenó a los integrantes del destacamento Colina). Al respecto, la sentencia reitera que:

“799 [...] Las pautas interpretativas de la Convención Americana de Derechos Humanos y los prin-

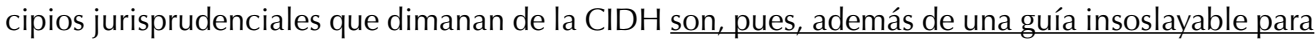
interpretar los derechos reconocidos en la Convención, vinculantes a este Tribunal. Esta doctrina, por lo demás, ha sido precisada por el Tribunal Constitucional en la sentencia número 0217-2002-HC/ TC, del siete de abril de dos mil dos, y reiterada en la sentencia número 2730-2006- PA/TC, del veintiuno de julio de dos mil seis, párrafo doce; y, enfatizada especialmente, por la Corte Suprema en la Ejecutoria vinculante número 18-2004, del diecisiete de noviembre de dos mil cuatro"6 .

En quinto y último lugar, la sentencia también es un reconocimiento al Informe Final de la Comisión de la Verdad y Reconciliación (CVR) del Perú, que ha sido y es aún hoy en día duramente atacado por diversos sectores políticos, militares y religiosos. En varios pasajes, la sentencia se basó en el informe final de la CVR, sosteniendo que es un documento público y válido. Al respecto, la sentencia sostiene:

“30. ¿Está probado que, como consecuencia del análisis realizado por diversas organizaciones internacionales y la Comisión de la Verdad y Reconciliación, se hizo saber a la opinión pública, y en el caso de la Comisión Interamericana de Derechos Humanos y Amnistía Internacional al gobierno del acusado ALBERTO FUJIMORI FUJIMORI, que durante los años mil novecientos noventa y uno - mil novecientos noventa y tres continuaba la violación de los derechos humanos en los marcos de la lucha contrasubversiva? Sí lo está".

6 Énfasis añadido. 


\section{Un antecedente crucial: la sentencia de la Corte Interamericana de Derechos Humanos en el caso de "La Cantuta"}

En la sentencia del caso "La Cantuta vs. Perú"7 (de noviembre del 2006) la Corte Interamericana de Derechos Humanos (CoIDH) estableció importantes líneas de interpretación respecto de los hechos probados: (i) el contexto de desapariciones forzadas y ejecuciones extrajudiciales, (ii) la indubitable existencia del destacamento "Colina" y (iii) la responsabilidad internacional del Estado peruano y, excepcional e indirectamente, sobre la responsabilidad de la propia Presidencia de la República que, en ese entonces, ejercía Fujimori:

96. Basta señalar en este capítulo que la Corte considera reconocido y probado que la planeación y ejecución de la detención y posteriores actos crueles, inhumanos y degradantes y ejecución extrajudicial o desaparición forzada de las presuntas víctimas, realizadas en forma coordinada y encubierta por miembros de las fuerzas militares y del Grupo Colina, no habrían podido perpetrarse sin el conocimiento y órdenes superiores de las más altas esferas del poder ejecutivo y de las fuerzas militares y de inteligencia de ese entonces, específicamente de las jefaturas de inteligencia y del mismo Presidente de la República $[\ldots]^{\prime \prime}$.

Sin duda esta sentencia contribuyó, entre otros factores, al otorgamiento de la extradición por parte de la Corte Suprema chilena. Al respecto, la Corte Suprema del Perú explicitó que:

"159 [...] valora positivamente que el Estado esté atendiendo su deber -derivado de su obligación de investigar- de solicitar e impulsar, mediante medidas pertinentes de carácter judicial y diplomá-

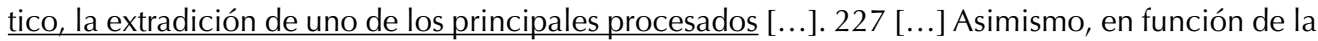
efectividad del mecanismo de garantía colectiva establecido bajo la Convención, los Estados Partes en la Convención deben colaborar entre sí para erradicar la impunidad de las violaciones cometidas en este caso mediante el juzgamiento y, en su caso, sanción de sus responsables ${ }^{\prime 9}$.

Fue evidente el mensaje no sólo para el Gobierno del Perú, sino también para el Gobierno de Chile.

\section{5. ¿De qué crímenes se le ha condenado?}

Tal como ya hemos adelantado, a Fujimori se le condenó por las matanzas de Barrios Altos y La Cantuta (homicidio calificado y lesiones graves) y los secuestros agravados del periodista Gustavo Gorriti y el empresario Samuel Dyer.

La matanza de Barrios Altos tuvo lugar el 3 de noviembre de 1991 y fue la primera acción criminal que perpetró el destacamento Colina en el marco de la nueva estrategia antisubversiva de Fujimori, la cual operaba en dos planos: uno público y legal, y otro secreto y criminal. La matanza de Barrios Altos fue una acción en respuesta al horrendo atentado que había sufrido un destacamento de los Húsares del Perú, guardia de honor del Presidente de la República y que consideró la información de inteligencia que establecía que las personas de Barrios Altos supuestamente formaban parte de una red senderista de vendedores ambulantes de helados que funcionaban como informantes.

Ese día, estos humildes comerciantes celebraban una "pollada"10 en el inmueble ubicado en Jr. Huanta 840, con el fin de recaudar fondos para financiar las obras de desagüe que requería dicha

\footnotetext{
Corte IDH. Caso La Cantuta Vs. Perú. Fondo, Reparaciones y Costas. Sentencia de 29 de noviembre de 2006. Serie C No. 162.

8 Énfasis añadido.

9 Énfasis añadido.

10 "Pollada" es una reunión social frecuente en sectores sociales de escasos recursos, en el que se toca música, se vende pollo a la parrilla y bebidas a un grupo de amigos o vecinos, con el objeto de obtener fondos para un propósito vecinal
} 
quinta, que era habitada por varias familias. Integrantes del destacamento Colina liderados por el capitán Santiago Martín Rivas, cubiertos con pasamontañas y apoyados por vehículos militares, usaron armamento de guerra y silenciadores $y$, sin mediar palabra alguna, dispararon en contra de estas personas desarmadas. Asesinaron a 15 personas, entre ellas un niño de 8 años de edad; otras quedaron gravemente heridas y lisiadas de por vida. La sentencia del caso Fujimori revela que luego del operativo los miembros del destacamento Colina retornaron a las instalaciones militares en la playa "La Tiza" a celebrar la acción y el cumpleaños del siniestro capitán Martín Rivas.

Posteriormente, en la madrugada del 18 de julio de 1992 -y tan sólo dos días después del feroz atentado terrorista en la calle Tarata en el distrito limeño, en el cual murieron muchos inocentes-, el destacamento Colina, liderado nuevamente por Martín Rivas, ingresó a la Universidad Nacional "La Cantuta" y secuestró a nueves estudiantes y a un profesor que vivían en la residencia universitaria. La sentencia determinó que estas personas fueron llevadas a un paraje solitario por la carretera Ramiro Prialé, donde fueron asesinadas de un tiro en la cabeza y sus cuerpos quemados y enterrados con cal. Poco tiempo después y con motivo de los insistentes rumores sobre el asesinato y las denuncias de los familiares, sus restos fueron retirados de dicho lugar y vueltos a enterrar en otro paraje solitario de Cieneguilla, donde fueron hallados tiempo después gracias a una investigación periodística de la revista "Sí". Dentro de la Universidad Nacional "La Cantuta" se había instalado una "Base acción cívica" del Ejército, que permitía a las fuerzas armadas tener bajo control dicha casa de estudios. Por tanto, el ingreso del destacamento Colina sólo pudo hacerse con la autorización de dicha base militar, tal y como se ha demostrado en la sentencia.

El secuestro del periodista Gustavo Gorriti tuvo lugar en la madrugada del día 6 de abril de 1992, dos horas después del golpe de Estado que esa noche había dado Alberto Fujimori. Un grupo de militares ingresó a la casa de Gorriti mientras otro grupo acordonó toda la calle; lo secuestraron y Ilevaron a los sótanos del Servicio de Inteligencia del Ejército (SIE) al costado de la comandancia general del ejército (edificio más conocido como el "Pentagonito"), donde permaneció incomunicado por dos días. Apenas fue puesto en libertad, Gorriti participó en una conferencia de prensa que dio Alberto Fujimori y le reclamó sobre el secuestro del que había sido objeto y su computadora incautada que no había sido devuelta; Fujimori, sin inmutarse, le respondió que su computadora le iba a ser devuelta de inmediato.

Finalmente, el 27 de abril de 1992, el empresario Samuel Dyer se disponía a tomar un vuelo hacia los Estados Unidos en el aeropuerto internacional "Jorge Chávez" de Lima en compañía de su hijo menor, cuando sin mediar información u orden de detención alguna, fue capturado y llevado a los sótanos del SIE, lugar en el que permaneció incomunicado por una semana hasta que logró huir gracias a la ayuda de algunos militares.

Nadie discutió durante el proceso, ni siquiera la defensa del ex mandatario, que estos crímenes se produjeron y que fueron perpetrados por personal militar. El debate se centró en si Fujimori era responsable o no de los mismos. Evidentemente, él no participó física ni directamente en ninguno de estos delitos, ni fue él quien apretó el gatillo. La acusación fiscal sostuvo que él fue "el hombre de atrás", el autor mediato de estos y otros delitos, que ejerció el control y lideró un aparato de poder organizado que tuvo como sus ejecutores directos al destacamento Colina y a Vladimiro Montesinos como jefe operativo y "representante directo" de sus decisiones. Es por ello que la sentencia lo condena como responsable mediato de estos crímenes, según un razonamiento judicial basado, entre otros aspectos, en: (i) prueba indiciaria (considera probados algunos hechos a partir de prueba indirecta o indiciaria), (ii) la concentración del poder en Fujimori y

(p.e. pintar el barrio o el edificio multifamiliar) o humanitario (p.e. comprar medicinas para un familiar o amigo gravemente enfermo). 
Montesinos, (iii) la existencia de una estrategia antisubversiva clandestina, (iv) la existencia de un aparato de poder organizado cuyo núcleo ejecutor fue el destacamento Colina, y (v) el posterior encubrimiento de tales delitos.

\section{Ratificación de la sentencia}

El 30 de diciembre del 2009 -mientras redactábamos el presente artículo- la Primera Sala Penal de la Corte Suprema confirmó en todos sus extremos esta sentencia condenatoria, resolviendo:

"I. Por Unanimidad: NO HABER NULIDAD en la sentencia expedida por la Sala especial de la Corte Suprema de Justicia [...] en el extremo que condenó a Alberto Fujimori Fujimori o Kenya Fujimori como autor mediato de la comisión del delito contra la vida, el cuerpo y la salud, en la modalidad de homicidio calificado [... $]^{\prime \prime 11}$.

Si bien la defensa de Fujimori ha anunciado que seguirá dando una batalla legal mediante un recurso de habeas corpus ante la justicia constitucional, consideramos muy poco probable que esta condena judicial sea modificada en el futuro, por lo que la única puerta de libertad -inconstitucional y contraria a la Convención Americana de Derechos Humanos- para el condenado Fujimori es la que ya han puesto en marcha sus seguidores: que su hija gane las elecciones del 2011 y, una vez en el poder, le conceda el indulto presidencial. Pero nadie cambiará ya el hecho irrefutable que el sistema de justicia peruano encontró culpable de delitos contra los derechos humanos a Alberto o Kenya Fujimori.

11 Página 258 de la sentencia. Énfasis añadido. 